\title{
Exploring the Impact of Reality Pedagogy: Understanding its Implementation on Urban Immigrant Students
}

\author{
Tanzina Taher*, Felicia Moore Mensah, Christopher Emdin \\ Teachers College, Columbia University, United States
}

Copyright $\subset 2017$ by authors, all rights reserved. Authors agree that this article remains permanently open access under the terms of the Creative Commons Attribution License 4.0 International License

\begin{abstract}
This ethnographic case study follows two urban immigrant students in their yearlong journey in an urban science classroom where the first two pedagogic tools of reality pedagogy (cogenerative dialogue and co-teaching) were implemented. This study examines the role reality pedagogy plays in the science classroom for these two students, while focusing on their social capital and how distributed cognition is used to frame understanding. The three emergent themes that were generated and observed among the two participants indicated that the implementation of the first two tools of reality pedagogy increased the two immigrant students' participation within their science classroom, increased opportunities for voice in the classroom, and increased ability to access the human and physical resources of the classroom for the participants' own benefit. The study revealed that both students' social capital was impacted and the frame of distributed cognition played a role in their science classroom participation. Implications relate to the importance of developing community within science classrooms for immigrant students.
\end{abstract}

Keywords Immigrant Students, Urban Science Classroom, Reality Pedagogy, Cogenerative Dialogue, Co-teaching

\section{Introduction}

Research in the field of education of immigrant students indicates that immigrant students "conceptualize [class] participation in ways that differ from the bulk of the literature, and these differences have important ramifications for current teachers and future research" [1]. For immigrant students, as Patchen [1] states, just by participating in the classroom such as answering questions, offering opinions, presenting group work, or asking questions, these common classroom acts have "the potential to expand an awareness to self, increase the capacity for tolerating dissent, and broaden the ability to support others while generating a more practical sense of community and safety." Furthermore, for immigrant students' class participation, "care" [2-4] from peers and teachers helps increase participation. When teachers "communicated more openly, asked students about themselves and their lives, provided comprehensible input, and did not embarrass or ignore them, or allow other students to do so," it fostered a sense of care and resulted in an increase in class participation among immigrant students [1].

Since there can exist a level of social discomfort among immigrant students in a given classroom that can potentially hinder their learning and academic performance, research in this area encourages broader communication among immigrant students with their teachers and peers in order to alleviate this sort of discomfort. As Skuza [5] indicates, "Underlying an immigrant's acculturation is the communication process.... After all, communication is a central and fundamental mode of human learning and expression." This study examines a recently developed perspective called reality pedagogy [6]. With its central goal being to support both teachers and students toward improving the experience of both groups in teaching and learning science in an urban academic environment, reality pedagogy in this study is examined via the lenses of social capital [7] and distributed cognition [8]. These two lenses are used in order to understand what role reality pedagogy, namely cogenerative dialogue and co-teaching, plays in the science classroom experiences of immigrant students.

\section{Conceptual Framework/Literature Review}

Emdin [9] coined the phrase reality pedagogy as an outgrowth of past research in urban classrooms and focuses primarily on understanding urban students and their culture within a particular social space, such as the science classroom. Parallel in some ways to critical pedagogy, reality pedagogy functions to develop students' consciousness about the sociopolitical factors that impact the teaching and learning process [11]. Toward meeting its goals, reality 
pedagogy engages five pedagogic tools, which involve students and their teacher collaborating together to improve the teaching and learning of science. These five pedagogic tools are: cogenerative dialogue (cogens), co-teaching, cosmopolitanism, and - more recently developed - context and content [6]. In this study, we focus on the implementation of the first two pedagogic tools (cogenerative dialogue and co-teaching).

Cogenerative Dialogue: The primary goal of cogenerative dialogues (cogens) is to make collective decisions about the responsibilities, roles, and rules that preside over students' classroom lives [12]. Cogens are discussions with students about what inhibits their engagement in the classroom. Thus, cogenerative dialogues are in essence dialogues that students have with their peers and teacher to co-create a plan of action for their class. The cogens allow teachers to teach in a more culturally relevant manner, as they allow teachers to hear and "take part in conversations that can shift teaching practices in ways that reflect student standpoints and insight into the inner-workings of the classroom" [11]. As the instruction becomes more culturally relevant, it is more effective because it is "based on students' thoughts and ideas instead of teachers' conceptions or assumptions about their students' culture" [11].

The structure of a cogen session that was implemented in this study was to have four to six students and their science teacher (during lunch, before or after school) discusses a science class they all are a part of. The teacher and students engage in a critical deconstruction of what happened in the classroom. Then, as a group, all decide at least one thing that the group can do to improve teaching and learning when they return to the classroom. In these dialogues, a small group of students are given the opportunity to reflect on their classroom learning, and, most importantly, provide their teacher with an insight into what can work well in the classroom from the students' perspective.

Co-teaching: Reality pedagogy defines co-teaching in two scenarios. In the first scenario, the student-teacher is considered as having more knowledge and expertise on how to best deliver the content to reach the rest of the class. Here, the student-teacher (or student-teachers) delivers the content in the way they feel is relevant to their peers in the class. Co-teaching methods in this first scenario call for a role reversal between the teacher and the student. In co-teaching, the teacher is both physically and symbolically positioned to learn from the student-teacher, while the student-teacher is allowed the opportunity to prepare and teach the lesson. Enacting co-teaching in this manner, the teacher "takes notes on the way the student enacts pedagogy, documents the specific examples the student uses, records the way the student interacts with peers, and learns how to teach in ways that reflect the realities of student experiences" [11]. The teacher here in the classroom thus plays the role of a novice learner. In developing the lesson-plan and preparing the content to teach, the teacher also plays a role in helping the student-teacher while providing necessary teaching materials, textbooks, or web resources, like lesson plans and any other instructional or content-related materials.

In the second co-teaching scenario, "The goal is to harness strengths (by allowing students to teach what they know well) and address content deficiencies (by allowing students to teach their peers who need help with content knowledge on specific topics).... It focuses on youth who feel responsible for each other's learning and the collective success of all students within the classroom" [11]. Here, students co-teach science content to one another on a one-to-one basis during class activities in the science class. Students are matched according to their strengths and weaknesses vis-à-vis specific content.

According to McGee and Keller [13], a good way to introduce youth to future professions is to expose them to those professions, and co-teaching in this manner does just that by providing them firsthand experience in teaching (and the teaching profession) and the content of science (and science-related professions). Further, according to Emdin's [6] research, both of these types of co-teaching play a role not only in empowering urban students toward the subject and content of science (particularly the specific contents the students teach), but also encouraging them to consider teaching and the field of science as career options. Both of these types of co-teaching were engaged in this study.

In co-teaching, the student's role in the classroom is not just the role of a learner but one who is more involved in the classroom instruction by taking ownership and responsibility of teaching to support learning. As teachers in the classroom, students feel more connected to their class and develop a stronger desire to learn within it. Such roles may be alternated among students as desired and include, but are not limited to classroom material manager, who maintains the books and instructional equipment; material and equipment distributor, who distributes handouts and equipment; computer/ technology manager, who looks after the technology (computers, laptops, LCD projector, smart-board) in the classroom; greeter of any visitors (teachers, administrators, and any other guests); discussion leader; and "even comedian, who is a designated person to provide comic relief in a class [11]. Such roles, as Emdin explains, "[allow] students to become invested in the daily operation of the classroom, which, in turn, [allow] the teacher to be more effective in the delivery of the content" [11].

Social Capital: Portes [17] states, "Whereas economic capital is in people's bank accounts, and human capital is inside their heads, social capital inheres in the structure of their relationships." Therefore, since utilization of one's social capital is shown to facilitate an effective learning environment for science, learning science requires productive teacher-student and student-student relationships. Thus, it is of great importance that educators look into the intricacies of the social capital students bring to the science classroom.

According to Coleman [18], the dense networks created by those who have shared social capital result in scenarios where everyone within a particular network is so deeply 
connected to everyone else in that network that the network is hard to penetrate by outsiders. He argues that within these types of scenarios, trust is growing, and group needs and concerns as co-defined by participants are being met and fulfilled. Burt [19] defines structural holes as the result of breaches in existent social networks that allow for the development of more complex forms of social capital through the diffusion of information. Such classroom dynamics as dense social networks and structural holes are explored in this study to further enlighten the experience of immigrant urban science students.

Figure 1 shows a representation of social capital as it is used in this study. For example, within the classroom structure, the social capital is formulated via social interactions that occur in the classroom. These social interactions foster dense networks, which may lead to negative social capital where outsiders of the dense networks are completely excluded and are unable to gain from the capital. In creating structural holes within these dense networks, negative social capital is alleviated, and where weak ties are allowed to be formed between new acquaintances, a new source of knowledge is found. Portes [17] further states that "to possess social capital, a person must be related to others, and it is those others, not himself, who are the actual sources of his or her advantage." In the present study, we use the social capital framework to conceptualize how the two immigrant youths obtain social capital while attempting to relate to their non-immigrant urban classmates to make the classroom environment functional for themselves.

Distributed Cognition: The human mind does not evolve in isolation from the social and material world. Several researchers propose that our brain is designed to take advantage of the minute-to-minute details of our bodies and the interaction of our bodies with the physical environment [20-21]. The activities in the human mind are interlaced, even inextricably, with the material and social world [22]. Most simply put, an example of a system of distributed cognition is a group of people working together. "In such a case, cognition is distributed across brains, bodies, and a culturally constituted world" [8]. A person working alone with, and even without, materials or tools is also considered an example of distributed cognition. "The point is that distributed cognition is not a kind of cognition at all, it is a perspective on cognition. Its chief value is that it poses questions in new ways and leads to new insights.... Distributed cognition sees real-world cognition as a process that involves the interaction of the consequences of past experience (for individual, group, and material world) with the affordances of the present. In this sense, culture is built into the distributed cognition perspective as at least a context for cognition" [8].

The ways in which cognition is distributed from a cultural point of view are: (a) between a culturally constructed environment and a person, (b) through time, and (c) in socially organized settings, among the people in that setting. In real-world interaction and activities of a science classroom, all of these sorts of distribution and interaction take place simultaneously. The distributed cognition perspective thus suggests that, along with the individuals in a given environment, the environment itself and the materials/tools in that environment are a source of support and knowledge. Thus, to form a system of distributed cognition, all parts of the culture of the learning environment come together. In this specific case study, toward setting up a system of distributed cognition, the culture and the pedagogic tools of reality pedagogy themselves played a role.

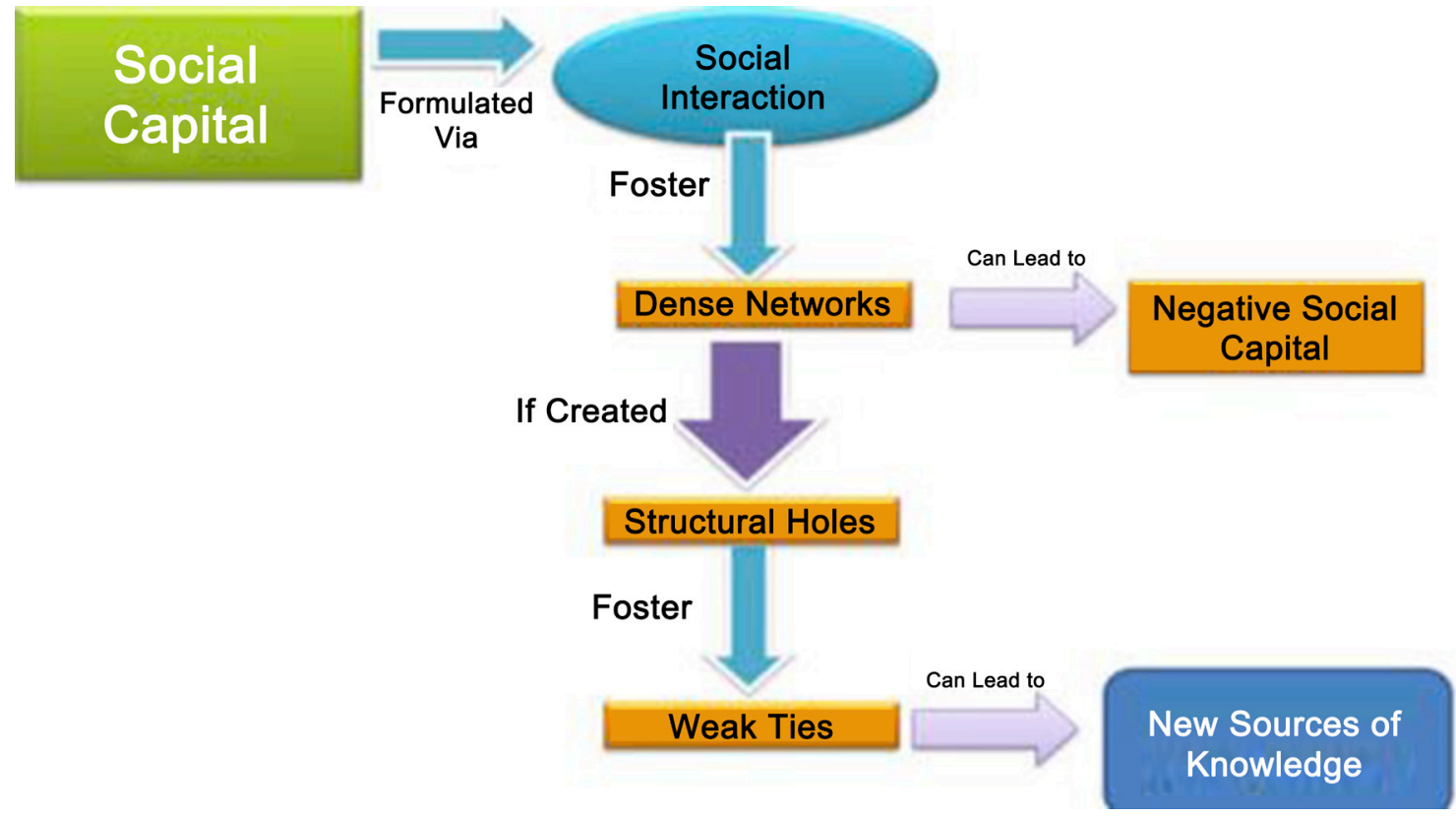

Figure 1. Social Capital as a Theoretical Frame 
Alac and Hutchins [23] propose that human interaction is a complex dynamic system and that "typical human-human interactions are composed of many elements, the meanings of which emerge from the network of relations among the elements" [8]. Vygotsky [24] suggests in his theory of the social origins of mind that we need to know more about the distributed ways of thinking within our mental activities and our thoughts that are woven inextricably in the actions of the material and social world. Toward this end, Hutchins [8] notes that with regard to human-human interaction, "much more work needs to be done to document the distribution of cognitive strategies across space, culture, and context."

Researchers of distributed cognition believe that "the attention to microstructure of interaction from the distributed cognition perspective leads to a reconceptualization of the individual-environment relationship and suggests that this newly conceived relation has important implications for the way we confront many sorts of cognitive and anthropological problems. In particular, it provides a new place to look for mechanisms that shape both the ontogenetic and the phylogenetic development of sociality" [8].

\section{Methodology}

\subsection{Setting and Participants}

Utilizing ethnographic qualitative research methods in this study, the first author visited the science classroom of the participants once a week. This was done not only to gain knowledge of the classroom environment but also to build a rapport with the students. This specific way of designing the study allowed for enhancement of a number of features of trustworthiness of the study, such as triangulation of multiple data sources to substantiate claims, "prolonged engagement" [25] in the research setting, and acquiring information to provide "rich, thick description" [26-27]. The school is a New York City public school (NYC Medical High, a pseudonym) that includes grades 7 through 12, with approximately 90 students in each grade. NYC Medical High was in its 7 th year at the time of the study. This study took place in the Fall 2010 and Spring 2011 academic year in the context of a 10th grade Living Environment science class in NYC Medical High. The school defined immigrant students as any student residing in the United States for five years or less. The Living Environment class included only two such students. With their consent, the study focused on them.

For each visit, the first author conducted cogenerative dialogue sessions with the two students and their teacher during the school's lunch period (all students in this class shared the same lunch schedule). As the year progressed, co-teaching in this classroom was done. This study focuses on two immigrant students, Rabina and Ilia (pseudonyms).

Rabina, age 14, was born in Lagos, Nigeria, and moved to New York at the age of 11 (three years prior to time of this study). She had resided with her mother in Nigeria and moved to New York with her older sister and now lives here with her father, step-mother, and two younger step-siblings. Rabina indicated that, while in Nigeria, she was very involved in her church and used to sing in her church's choir, which she dearly misses. She mentioned that her involvement at her church in Nigeria allowed her to make good friends, as her church choir group included students from her school, and she was able to get to know and spend time with them more intimately and frequently during weekly choir practices. Though Rabina and her family attended a church in New York, she was not involved in the church's choir. The church her family visited was quite far from her residence, which limited her visits and participation in church activities, except during holidays.

In class, Rabina appeared to be a quiet and shy student, and according to her science teacher, Mr. F, she was mindful of her academic performance. Rabina explained that after moving to NYC, she struggled with her Nigerian accent, particularly in school. She generally participated in her classes in Nigeria and recalled that when she volunteered to participate in her 8th grade class at NYC Medical High, the students ostracized her not only because of her accent, but also because she volunteered to participate. Rabina further indicated that she learned a lot about the American culture, such as how to speak with an American accent and using American expressions and colloquialisms while interacting with her younger step-siblings and watching television.

Ilia, age 15, is a Hispanic student from Puerto Rico. She was born in Puerto Rico and moved to New York with her family at the age of 10. Ilia indicated that it was due to her father's change of post in his job that she and her family decided to move to New York. Ilia indicated that her life here was not very different from the life she had in Puerto Rico, as the school system and environment in Puerto Rico were very similar to what she encountered here. The biggest difference in her life after moving here, she pointed out, was that her extended family did not live nearby. Her extended family (grandmother and aunts, particularly) helped raise her. She indicated that she used to visit her extended family every summer after moving to New York until last summer, when she joined a dance congress in New York. Dancing, Ilia indicated, was a big part of her life that she greatly enjoyed and considered as an outlet. She was involved in a dance group from a very young age in Puerto Rico and was very happy that her mother was able to find a similar studio last year in New York that she joined.

Ilia was one of the more talkative students in the class and appeared to communicate with only a certain number of students that she sat in close proximity to in the science class. Though the school system and environment in New York were similar to that of Puerto Rico, the cultural dynamics of the student population, Ilia indicated, were a noticeable difference she experienced when she first came here. Ilia expressed that she often felt excluded by other Hispanic students, particularly by students from the Dominican Republic. For example, in her 7th grade class (when she first 
moved to New York), the majority of the student population was from the Dominican Republic. Though this was the case, Ilia specified that over the year this difference in cultural background did not remain as pronounced as it first was as she became more familiar and accustomed to the culture in New York. Ilia pointed out that her "salsa dance" group now in Brooklyn, NY has individuals from various Hispanic/Latino ethnicities (Mexican, Dominican, Puerto Rican), coming from all around New York. Among them, they share common interests, such as salsa dancing, and Ilia enjoys their friendship.

\subsection{Design/Procedure}

This study addresses two research questions: Which facets of the experience of participating in reality pedagogy are most valuable to the immigrant science students? And, how does reality pedagogy contribute to the social capital of immigrant students? We chose to conduct an ethnographic case study within the methods of qualitative research, as this approach offers not only a "complex, detailed understanding" through the ethnographic research approach [26], but it also offers a deep descriptive level of understanding that provides an "experiential perspective ... that emerges from the context itself" [28]. A case study design was used to gain an "in-depth understanding of the situation [reality pedagogy] and meaning for those involved. The interest was in "the process rather than outcomes, in context rather than a specific variable, in discovery rather than confirmation" [25]. Therefore, this ethnographic case study examined the implementation of the first two C's of reality pedagogy - cogenerative dialogue and co-teaching - and how they impacted two immigrant students' social capital, and how distributed cognition played a role in this process.

\subsection{Data Collection}

Three data sources were used to inform the research questions. Specifically, the semi-structured interviews with two immigrant students (one from Puerto Rico, the other from Nigeria) and their science (Biology) teacher, weekly classroom observations, and weekly cogenerative dialogues sessions were conducted over one academic year (September 2010-June 2011). All interviews, observations, and dialogues were video-recorded.

\subsubsection{Interviews}

The two immigrant students were interviewed in order to gain the perspective of the immigrant population of the class regarding the impact of reality pedagogy. The individual interviews of the two immigrant students took place three times in the fall semester and three times in the spring semester. All interviews were conducted using the interview questions on Appendix A. Each student and the teacher were interviewed at distinct times of the academic year. In total, Rabina and Ilia were interviewed six times each in the course of the year, three interviews being in the Fall semester (October/November) and three in the Spring semester
(March/April), and the final interview (June). The teacher was also interviewed in order to gather his perspective on the impact of reality pedagogy. He was interviewed four times in the course of the year, two times in the Fall semester (November/December) and two times in the Spring semester (March/May). All interviews were 15-30 minutes in length and were semi-structured in nature. That is, though all questions noted in Appendix A were asked and answered, additional clarification and at times conversational questions were part of the interviews. These additional questions and conversations made the interviewee feel more comfortable, and at times clarification of what was said was gained [28]. Student interviews provided insight into the individual students' experiences, and finally the teacher's interviews allow for an addition perspective on the implementation of this set of pedagogic tools toward a more deep and rich understanding of the phenomenon.

\subsubsection{Classroom Observations}

Classroom observation began in September and lasted until the first week of June. In total, 34 class sessions were observed and video-recorded. The video camera was stationed at the back of the class, making sure to capture the view of the whole class. Four small audio-recorders were also strategically placed around the four corners of the classroom.

Additional field notes and memos were collected during transcribing the video data. Data were also collected via informal conversations with the students intermittently during weekly visits. Field notes of these informal conversations were also noted at the end of a visiting day if such a conversation took place on a given visiting day. These informal conversations were not video- or audio-recorded, as they took place sporadically.

\subsubsection{Cogenerative Dialogues}

Cogenerative dialogue sessions began in October and lasted until late December in the Fall 2010 semester. Nine cogenerative dialogue sessions took place and were video-recorded in the fall semester. In the Spring 2011 semester, 14 cogenerative dialogue sessions took place. The study thus includes 23 video-recorded cogenerative dialogue sessions. The cogenerative dialogue sessions were guided using the questions in Appendix B; however, additional questions and topics were discussed as brought up by the teacher and the students themselves. Though the cogenerative dialogue sessions are one of the two C's being implemented in this study, these sessions were also key in understanding the participants' development (via their interactions with other participants in the sessions) throughout the progression of the year.

\subsection{Data Analysis}

For data analysis, constructivist grounded theory 
maintains that "both data and analyses are social constructions that reflect what their production entailed" and "any analysis is contextually situated in time, place, culture, and situation" [29]. Parallel to this notion, we approached the study via "interpretive inquiry," in which "researchers make an interpretation of what they see, hear, and understand" [26]. All data collected for this study were analyzed using the qualitative data analysis software known as Atlas.ti [30]. All video- and audio-recorded data were transcribed and coded for the social capital frame, whereas further "focused coding" allowed the first author to "synthesize and explain larger segments of data" [29] or analytic categories, leading to the emergence of the "distributed cognition" frame. Further, the codes and data were closely studied again to confirm the aspects of the data that identified with the "social capital" and "distributed cognition" frame. The theoretical frame of social capital was discerned when the pilot version of this study was conducted two years prior to this study, and it was with this lens that this study was conducted. The "distributed cognition" frame was emergent from the findings of the study.

In the analysis of the data collected for the study, authors were in essence interested in and looking for an overall progression over time of the implementation of the two Cs. In observing the two immigrant students, for example, if, over time, one of the two students appeared to be more engaged in class, it allowed for a point of interest to investigate. So, during the classroom observations over time, if, for instance, one of the students was talking in regard to the science content being taught in class more and more as the semester progressed, it provided a point of interest to be investigated. In this case, in a consecutive interview, the first author questioned the student about this behavior and looked in her response for an affirmation or negation of whether she felt this increase in engagement in the science class was a reflection of the implementation of the cogenerative dialogue and co-teaching. Also, in this specific student's cogenerative dialogue sessions, the first author looked to see whether she was either more or less engaged in the dialogues as the year progressed and later asked the students in their individual interviews whether they felt this increase in engagement in the science class and the dialogue sessions was a reflection of the implementation of the cogenerative dialogue itself and co-teaching. This either confirmed that implementation of the cogenerative dialogues and co-teaching had an impact in the student becoming more engaged in the class or confirmed that the set of pedagogic tools did not have an overall impact on this specific student. This is also the method via which each of the three sources of data was triangulated. In the findings below, we present the themes generated from analysis and corroborated through peer debriefing and member checking [31].

\section{Findings}

From the data analysis, three emergent themes were observed and were generated among the two participants of the study, Ilia and Rabina, and the science teacher, Mr. F. Below briefly we discuss these three themes.

\subsection{Theme 1: Cogens Increase Participation in the Science Classroom}

Toward the beginning of the semester, we noticed that the biology class was quite noisy and the teacher had a difficult time getting students' attention. Students who sat closest to each other talked together, mostly about topics unrelated to the science lesson. Not much communication took place between students who sat further way. Both the teacher and students in the initial cogenerative dialogues and interviews indicated that there were "cliques" in the classroom. Students from two separate 9th grade cohorts were mixed to form this 10th grade cohort. Students indicated in the initial cogenerative dialogue sessions that some students in these two separate cohorts did not get along very well, resulting in confrontations and arguments during class. Cliques formed within the initial 9th grade cohorts, which further caused individual students in the class to stay within their own circle of classroom friends.

The cogen sessions included a mix of students from the whole class, who either volunteered to participate or randomly invited to participate in the cogen sessions. The cogen sessions included students from the different cliques or social groups of the classroom. The cogens created a space and allowed opportunities for Ilia not only to voice her concerns about the classroom environment but also to communicate with students outside her social group. The cogens were held once a week during students' lunch period in the same science classroom.

At a cogen session (and also in an informal conversation), Rabina and Ilia both voiced that the school took nearly a month to establish class schedules. This left many students frustrated, as they were not able to follow a given class from the beginning of the semester. Rabina indicated in one cogen session it took "so long" for the school to establish students" schedules that she became frustrated. In support, Ilia stated, "it took them like three weeks in September and they still don't get it right!" Here, both Rabina and Ilia were given a space to express their thoughts and frustrations about their similar or shared circumstance regarding schedules and classes. Though both students were from separate cliques or social groups in the classroom, they found support and comfort in the cogens, which led to more ease when it came to engaging with one another in future cogens and in classrooms activities during biology class. For instance, Rabina from participating in cogens communicated with students from other social groups in the science classroom. She stated: "I never talked to Monica until at the cogen that day. I helped her when we did the co-teaching on parts of the cell. It was me, Monica, Brian, and Maria in the group, and we presented." Overall, the cogens increased participation of students in the science classroom as students had a space to 
communicate with each other while they discovered commonalities among themselves.

\subsection{Theme 2: Increased Opportunities to Voice Concerns about the Science Classroom}

Ilia also had the opportunity to communicate with students she normally did not communicate with. However, Ilia was one of the students who was involved in a clique in the biology class. Not afraid to vocalize herself, Ilia often called out in class and engaged in conversations with surrounding peers in her clique when Mr. F was teaching. In a cogen, Ilia admitted to calling out: "I know I call out.... I can't help it ..." (smiles). Ilia joined the cogenerative dialogue sessions in the second session. She seemed comfortable to talk with peers and $\mathrm{Mr} . \mathrm{F}$ in the cogen sessions. At times she was even playful with Mr. F, who encouraged a relaxed and friendly environment so that the more reserved students, like Rabina, would feel at ease to participate.

Cogens also allowed Ilia to voice her opinions about specific academic concerns, such as learning biology content or scientific terminology. Particularly, Ilia brought up the difficulty she had with understanding scientific terms, stating in cogens: "It's difficult to understand those big science words. You [Mr. F] have a big vocabulary for the test. But Mr. F your wording!" In the cogens, both Ilia and Rabina, along with other students, discussed and worked with Mr. F so that he could better explain the scientific terms in his lessons. One solution Ilia, Rabina, and others students established was to co-plan with Mr. F. They suggested a glossary in the back of their notebooks, which they decided to add daily when learning new scientific words. This glossary was individual to each student and included scientific words particular students had difficulty with. The glossary also contained English words that immigrant students newly learned that day.

Next to voicing opinions about specific academic concerns, Ilia along with a number of her classmates suggested re-arranging the classroom seating towards alleviating some of the tension students were experiencing due to the existing cliques in the classroom. Mr. F honored this suggestion, which in turn empowered the students, giving them a sense of ownership and place in the classroom.

Cogens not only allowed Ilia to voice her concerns about understanding scientific terminology, but also opened the table to other academic concerns that immigrant students like Rabina had. For example, Rabina shared that she had difficulty with graphs in a recent biology exam in the class. Upon voicing that "the graph was hard," Rabina received immediate support from Ilia, who stated, "I just didn't know what to put! Oh my god! I just put anything [for the graph]," and other students also concurred. Raising her concern about graphing, Rabina gained peer support, and her comment also resulted in a more vigorous review of graphs before the next science exam. Thus, the cogen sessions for Ilia and Rabina expanded their social network and allowed them to receive better instruction in the science classroom.

\subsection{Theme 3: Increased Access the Human and Physical Resources from Cogens and Co-teaching}

For Ilia and Rabina, their social networks or the number of students they regularly communicated with in their science class was broader due to their participation in cogens and co-teaching. As noted above in the quote from Rabina, she communicated and worked together with Monica, Brian, and Maria (three students with whom she generally did not even talk with in class) when co-teaching the topic on the parts of the cell together with them. While attaining a broader source of new knowledge, Ilia maintained communication with her co-teaching group and other co-teaching groups, as she indicated in an interview: "Me and my group got the chart idea from Maria's group ... it helped out when we presented ... we gave them our construction paper ... that helped them out." This sort of sharing of ideas and human capital (co-teaching presentation methods in this case) and physical resource (construction paper in this case) progressively became part of the students' practice. Rabina mostly engaged in and accessed the human and physical resources of her co-teaching group, whereas Ilia accessed human and physical resources of both her own group and other co-teaching groups. The co-teaching groups were formed based on the topics students were interested in. Thus, if a number of students (no more than 4 to 5) were interested on a given topic, they together co-taught that topic. The structure of co-teaching and the cogens provided access to attain human and physical resources, which in turn benefited both Ilia and Rabina in their co-teaching activities. Interview quotes from Rabina and Ilia indicated this point: Rabina stated, "I got the DNA and protein thing better after we talked it out in my group before co-teaching it." And, Ilia stated, "I like how we charted out the plant cell versus the animal cell in my group.... I got the chart idea from Maria's group ... it's more clear to me in the chart."

\section{Discussion and Implications}

The findings of this study present that the implementation of the 2 C's of reality pedagogy, cogenerative dialogue and co-teaching, generate three major themes among the two participating immigrant students, Rabina and Ilia. These themes explain that while participating in cogens and co-teaching activities, Rabina and Ilia are able to increase participation with their class's social networks and increase opportunities for their voices to be heard in the classroom, and finally, participating in the $2 \mathrm{C}$ 's increases their ability to access the human and physical resources of classroom for their own benefit. The communication in both the cogens and co-teaching allows thoughts of one person or even groups to be distributed or shared. In Rabina's case, she mostly practices distributed cognition when working with her 
co-teaching group, whereas Ilia practices distributed cognition more broadly to include her group and other co-teaching groups in the class.

The findings show that participation in the $2 \mathrm{C}$ 's allows Rabina and Ilia to increase their social capital. Within the frame of distributed cognition, their increase in social capital caters to their development as science students and members of the science as they progress through the year. As Rabina and Ilia participate in cogens, they form weak ties with one another and other participating students, and when they return to the classroom after participating in cogens, these weak ties innately result in the creation of structural holes.

More specifically, viewing cogens and co-teaching via the social capital lens, the cliques or dense networks of the initial social groups in the classroom appear to exclude Rabina and students like her from participating in the social networks of her classroom. The cogens themselves and the communication Rabina has with her peers in cogen sessions allows for structural holes to be created with these dense networks. Structural holes are also physically created when the classroom seating is re-arranged (per students' suggestion), which together with cogens allow Rabina to create weak ties with the students she interacts with. This sort of interaction creates a new source of knowledge (social and academic) for her, which further encourages her to take part in co-teaching activities, even further fostering her social and academic knowledge and social capital overall.

In Ilia's case, participating in cogens creates structural holes in her own classroom cliques or dense networks, where in the cogen sessions, she begins to communicate with students like Rabina, who are outside Ilia's social group and with whom she never communicated until the cogen sessions. The classroom seating re-arrangement also creates physical structural holes. For Ilia the cogen sessions allow her to interact in other social groups where she is able to recognize that students outside her own social groups share similar concerns noted previously. These sorts of interactions initiate weak ties with the students she interacts with in the cogens and carries over to the classroom. She appears to utilize these new sources of knowledge with most of this during co-teaching activities and further fosters her social capital.

Due to progressive implementation of cogens and also to the classroom seating re-arrangement (co-planned and decided in cogen sessions) and the implementation of co-teaching, most dense networks are either no longer present or no longer as strong as at the beginning of the school year. Moreover, in both of Rabina and Ilia's cases, the implementation of the 2 C's of reality pedagogy fosters social interaction, thus allowing these immigrant students to gain and share social capital with their peers. Via the co-teaching activities, these dense networks are further broken down, allowing students like Rabina-who has previously experienced negative social capital from her peers (i.e., being excluded from dense networks, unable to gain any capital as an outsider) - to create weak ties with her peers. She gains new knowledge and from new relationships from the cogens and co-teaching.

Both cogens and co-teaching also foster the distributed cognition frame. The frame of distributed cognition is deeply embedded in the structural design and principal concept of cogenerative dialogue sessions and co-teaching, as by design both foster the sharing of ideas and collaboration "across brains" [8]. Though there are others who may debate that distributed cognition is more than collaboration, we argue here that cogens and co-teaching are ingrained at the core of the basic concept of distributed cognition. Hutchins [8] explains that distributed cognition is a perspective of cognition. A simple example could be a group of people working together. Here, "cognition is distributed across brains, bodies, and a culturally constituted world" [8].

Given this is our point of interest, the first two tools of reality pedagogy - cogenerative dialogue and co-teaching - is comparable to the distributed cognitive perspective. Both of these pedagogical tools allow for collaboration among a group of students and their teacher. In cogenerative dialogue group sessions in this study, distributed cognition is practiced while students co-plan a course of action for their science class along with their teacher. All share ideas and eventually execute the co-planned ideas, as demonstrated in their collaboration in rearranging the class seating and establishing a system of having individual glossaries. In addition, in the implementation of co-teaching, students work with their peers in groups and with their teacher while discussing science content in order to gain clarification for themselves and to teach each other the necessary science content. This transfer and distribution of thoughts and explanations are exemplary of distributed cognition. Hutchins [8] further contributes that "a system of multiple interacting subsystems can provide a solution more easily than trying to get all of the constraints out of a single subsystem" (p. 394). In the implementation of both cogenerative dialogues and co-teaching in this study, distributed cognition is practiced, while these two students co-plan and collaboratively work with their peers.

\section{Conclusions}

This study sheds light on the experiences of two urban immigrant students in their journey in an urban science classroom. The first two pedagogic tools of reality pedagogy, cogenerative dialogue and co-teaching, are implemented in their science class. As the findings indicate, the two immigrant students become more involved in their science class. The use of cogenerative dialogue and co-teaching foster their social capital and assist in building their knowledge via the distributed cognition frame. This study highlights that reality pedagogy raises students' social capital and the perspectives of distributed cognition. In this way, reality pedagogy creates a socially supportive space for immigrant students and promotes overall growth of students 
in urban classrooms. Moreover, for both these immigrant students, the implementation of reality pedagogy allows them to gradually become full participants in their science classroom while creating a structure and space conducive to their learning and class participation.

\section{Appendices}

\section{Appendix A. Interview Questions}

\begin{tabular}{|c|c|c|}
\hline & Questions for Students & Questions for Teacher \\
\hline Autumn 2010 & $\begin{array}{l}\text { 1. How are the cogenerative dialogues you have with } \\
\text { your peers and teachers of your science class helpful } \\
\text { or not helpful overall when you come back to your } \\
\text { science class? } \\
\text { *2. How is co-teaching in your science class helpful } \\
\text { or not helpful overall in your science class? } \\
\text { 3. Would you say that compared to your other } \\
\text { classes, in science class you are or feel different due } \\
\text { to cogenerative dialogues and/or co-teaching? If so, } \\
\text { how? }\end{array}$ & $\begin{array}{l}\text { 1. How are the cogenerative dialogues you have with your students } \\
\text { helpful or not helpful overall when you come back to your science class? } \\
* 2 \text {. How is co-teaching in your science class helpful or not helpful } \\
\text { overall in your science class? } \\
\text { 3. Would you say that compared to your other science classes you are } \\
\text { currently teaching, (where cogens and co-teaching is not implemented) } \\
\text { the implementation of cogenerative dialogue and/or co-teaching in this } \\
\text { class had an impact on this class over all so far? If so, how? }\end{array}$ \\
\hline Spring 2011 & $\begin{array}{l}\text { 1. How are the cogenerative dialogues you have with } \\
\text { your peers and teachers of your science class helpful } \\
\text { or not helpful overall when you come back to your } \\
\text { science class? } \\
\text { 2. How is co-teaching in your science class helpful or } \\
\text { not helpful overall in your science class? } \\
\text { 3. Would you say that compared to your other } \\
\text { classes, in science class you are or feel different due } \\
\text { to cogenerative dialogues and/or co-teaching? If so, } \\
\text { how? }\end{array}$ & $\begin{array}{l}\text { 1. How are the cogenerative dialogues you have with your students } \\
\text { helpful or not helpful overall when you come back to your science class? } \\
\text { 2. How is co-teaching in your science class helpful or not helpful overall } \\
\text { in your science class? } \\
\text { 3. Would you say that compared to your other science classes you are } \\
\text { currently teaching, (where cogens and/or co-teaching is not } \\
\text { implemented) the implementation of cogenerative dialogue and/or } \\
\text { co-teaching in this class had an impact on this class over all so far? If so, } \\
\text { how? }\end{array}$ \\
\hline
\end{tabular}

Note. *= If co-teaching has not been implemented before the time of the interview, this question will not be asked to the students and the teacher.

\section{Appendix B. Guiding Questions for Cogenerative Dialogues}

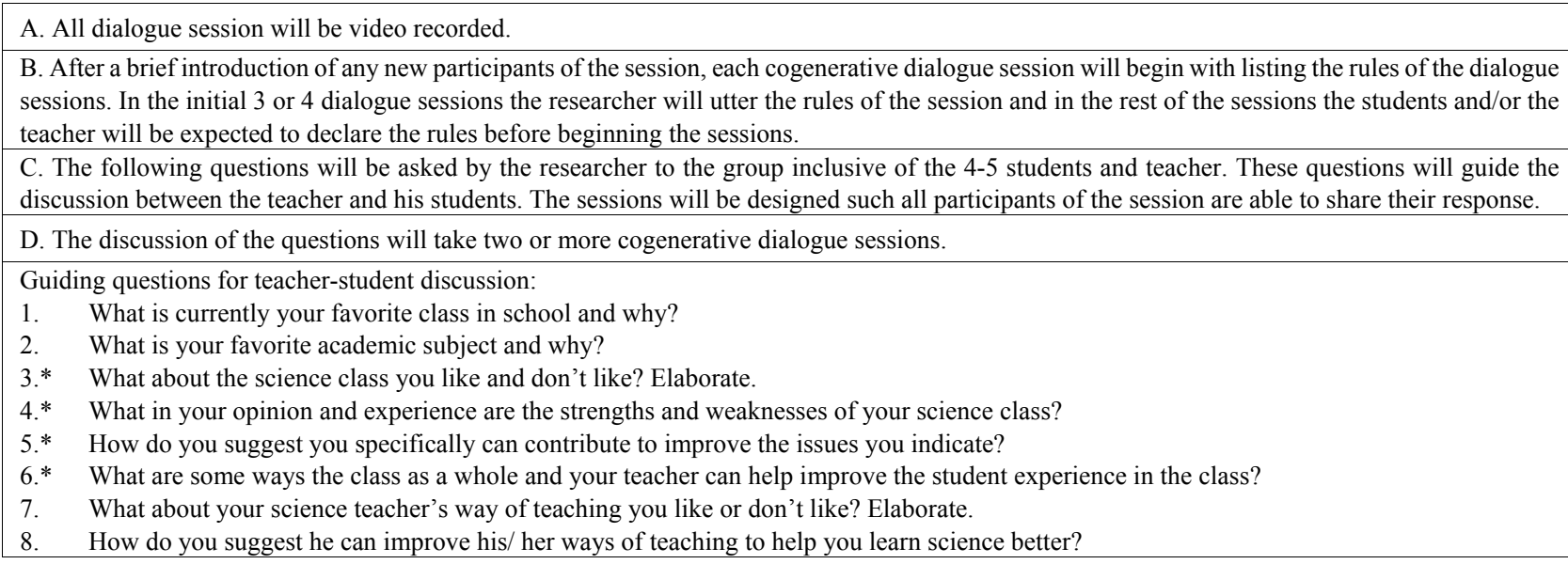

Note. $*=$ the teacher will be asked to respond to these questions as well. 


\section{REFERENCES}

[1] T. Patchen. Prioritizing participation: Five things that every teacher needs to know to prepare recent immigrant adolescents for classroom participation, Multicultural Education, Vol.12, 43-47, 2005.

[2] N. Noddings. Caring: A Feminine Approach to Ethics and Moral Education, Berkeley, California, United States, 1984.

[3] N. Noddings, The Challenge to Care in Schools: An Alternative Approach to Education, Teachers College Press, New York, New York, United States, 1992.

[4] A. Valenzuela, Subtractive Schooling: Mexican Youth and the Politics of Caring, State University of New York Press, Albany, New York, United States, 1999.

[5] J. Skuza. Understanding the experiences of immigrant adolescents: Acculturation is not the same as assimilation. In P. Witt, L. Caldwell (Eds.), Recreation and Youth Development, Venture Publishing, State College, Pennsylvania, United States, 2005.

[6] C. Emdin, Reality pedagogy: Hip hop culture and the urban science classroom. In W. M. Roth (Ed.), Taking a Stand(point), Science Education from People for People (pp. 70-89), Routledge, New York, New York, United States, 2009.

[7] P. Bourdieu. Outline of a Theory of Practice, Cambridge University Press, Cambridge, England, 1997.

[8] E. Hutchins. The distributed cognition perspective on human interaction. In N. J. Enfield, S. C. Levinson (Eds.), Roots of Human Sociality: Culture, Cognition and Interaction, Berg Publishers, New York, New York, United States, 2006.

[9] C. Emdin, Exploring the contexts of the urban science classrooms. Part 1: Investigating corporate and communal practices, Cultural Science Education, Vol.2, 319-350, 2007.

[10] C. Emdin, Exploring the contexts of the urban science classrooms. Part 2: The emergence of rituals in the learning of science, Cultural Science Education, Vol.2, 351-392, 2007.

[11] C. Emdin, Moving beyond the boat without a paddle: Reality pedagogy, Black youth, and urban science education, The Journal of Negro Education, Vol.80, No.3, 284-295, 2011.

[12] W. M. Roth, K. Tobin, A. Zimmerman, Co-teaching/ cogenerative dialoguing: Learning environments research as classroom praxis, Learning Environments Research, Vol.5, $1-28,2002$.

[13] R. McGee, J. L. Keller, Identifying future scientists: Predicting persistence into research training, CBE Life Science, Vol.6, 316-331, 2007.
[14] K. A. Appiah, Cosmopolitanism: Ethnics in a World of Strangers, Norton, New York, New York, United States, 2006.

[15] J. Field, Social Capital And Lifelong Learning, Policy Press, Bristol, England, 2005.

[16] A. Calabrese Barton, Urban science education studies: A commitment to equity, social justice and a sense of place, Studies in Science Education, Vol.38, No.1, 1-37. 2002.

[17] A. Portes, Social capital: Its origins and applications in modern sociology, Annual Review of Sociology, Vol.24, 1-24, 1998.

[18] J. S. Coleman, Social capital in the creation of human capital, American Journal of Sociology, Vol.4, S95-S121, 1988.

[19] R. S. Burt, Structural Holes: The Social Structure of Competition, Harvard University Press, Cambridge, Massachusetts, United States, 1992.

[20] A. Clark, Mindware: An Introduction to the Philosophy of Cognitive Science, Oxford University Press, Oxford, England, 2001 .

[21] S. Quartz, S., T. Sejnowski, Liars, Lovers, and Heroes: What the New Brain Science Reveals about How We Become Who We Are, Morrow, New York, New York, United States, 2002.

[22] M. Tomasello, The Culture Origins of Human Cognition, Harvard University Press, Cambridge, Massachusetts, United States, 2001.

[23] Alac, E. Hutchins, ????, 2004.

[24] L. S. Vygotsky, Thought and Language, MIT Press, Cambridge, Massachusetts, United States, 1986.

[25] S. B. Merriam, Qualitative Research and Case Study Applications in Education, Jossey-Bass, San Francisco, California, United States, 1998.

[26] J. W. Creswell, Qualitative Inquiry and Research Design: Choosing among Five Approaches (2nd ed.), Sage, Thousand Oaks, California, United States, 2007.

[27] Y. S. Lincoln, E. G. Guba, Naturalistic Inquiry, Sage, Newbury Park, California, United States, 1985.

[28] E. G. Guba, Y. S. Lincoln, Effective Evaluation, Jossey-Bass, San Francisco, California, United States, 1981

[29] K. Charmaz, Constructing Grounded Theory: A Practical Guide Through Qualitative Analysis, Sage, London, England, 2006.

[30] T. Muhr, Atlas.ti (Version 5.2 for Windows). Atlas.ti Scientific Software Development GmBh, Berlin, Germany, 1997/2005.

[31] E. G. Guba, Y. S. Lincoln, Judging the quality of fourth generation evaluation, In Fourth Generation Evaluation, Sage, Newbury Park, California, United States. 